\title{
Evaluation of functional mobility of patients with stroke sequela after treatment in hydrotherapy pool using the Timed Up and Go Test
}

\author{
Avaliação da mobilidade funcional do paciente com sequela de AVC após tratamento na \\ piscina terapêutica, utilizando o teste Timed Up and Go
}

\begin{abstract}
Daniel Gonçalves dos Santos ${ }^{1}$, Andréa Sanches Navarro Pegoraro ${ }^{1}$, Carolina Vilela Abrantes ${ }^{1}$, Fabio Jakaitis ${ }^{2}$, Silvia Gusman ${ }^{1}$, Simone Cristina Bifulco ${ }^{1}$
\end{abstract}

\begin{abstract}
Objective: To evaluate the functional mobility of patients with stroke over 12 sessions of hydrotherapy. Methods: Ten stroke patients aged between 5 and 85 years were evaluated by means of the Timed Up and Go test, which contains some items, such as balance, walking speed, changing directions, and standing up from a seated position. The study patients performed the test before and after each hydrotherapy session (total of 12 sessions). Each individual was compared to him/ herself both short-term (pre- and post-therapy) and long-term (after 12 therapy sessions). Result: Comparing baseline and after 12 sessions, it was noted that the 10 patients improved their performance, with a decrease in time to execute the Timed Up and Go test. Conclusion: An exercise program in a hydrotherapy pool was beneficial for functional mobility performance improvement in stroke patients.
\end{abstract}

Keywords: Physical therapy modalities; Hydrotherapy; Stroke/ rehabilitation; Postural balance; Gait; Stereotypic movement disorder

\section{RESUMO}

Objetivo: Avaliar a mobilidade funcional de pacientes com acidente vascular cerebral no decorrer de 12 sessões de hidroterapia. Métodos: Foram avaliados 10 pacientes com acidente vascular cerebral com idades entre 5 e 85 anos por meio do teste Timed Up and Go, que contém itens como equilíbrio, velocidade da marcha, mudança de direção e transferência de sentado para em pé. Os pacientes do estudo realizaram o teste antes e depois de cada sessão de hidroterapia (total de 12 terapias). Cada indivíduo foi comparado com ele mesmo, a curto prazo (pré e pós-terapia) e a longo prazo (após 12 terapias). Resultado: Comparados no início e ao final das 12 sessões, verificou-se que os 10 pacientes melhoraram sua performance, apresentando diminuição do tempo na execução do teste Timed Up and Go. Conclusão: 0 programa de exercícios em piscina terapêutica foi benéfico para melhora da performance da mobilidade funcional de pacientes portadores de acidente vascular cerebral.

Descritores: Modalidades de fisioterapia; Hidroterapia; Acidente vascular cerebral/reabilitação; Equilíbrio postural; Marcha; Transtorno de movimento estereotipado

\section{INTRODUCTION}

It is estimated that annually 20 million new cases of stroke occur worldwide. Of this total, approximately five million individuals may die. The remaining 15 million are non-fatal cases of stroke, and one third of them evolve with some neurological sequela. Thus, it constitutes one of the main causes of death and disability all over the world ${ }^{(1)}$.

Stroke has clinical manifestations that reflect the site and extent of the vascular lesion ${ }^{(2)}$. Lesions of the corticospinal system after a stroke interfere in daily activities, mobility and communication. Patients with stroke sequelae demonstrate difficulty in controlling the beginning of movement, as well as voluntary motor control $^{(3)}$. The primary cause of this interference is spasticity, compromising the ability of the patient to produce and regulate voluntary movement. Spasticity may result in static deformities; nevertheless, it may also alter

\footnotetext{
Study carried out at Rehabilitation Center, Hospital Israelita Albert Einstein - HIAE, Sao Paulo (SP), Brazil.

${ }^{1}$ Hospital Israelita Albert Einstein - HIAE, São Paulo (SP), Brazil.

${ }^{2}$ Hospital Israelita Albert Einstein - HIAE, São Paulo (SP), Brazil; Universidade Bandeirante - UNIBAN, São Paulo (SP), Brazil;

Corresponding author: Daniel Gonçalves dos Santos - Avenida Albert Einstein, 627\701 - Pavilhão Vicky e Joseph Safra - Morumbi - São Paulo (SP), Brasil - Tel.: (11) 2151-1233 - Ramal: 74564 -

E-mail: danyielsantos@hotmail.com.

Received on: Jul 21, 2011 - Accepted on: Sep 13, 2011

Conflicts of interest: none
} 
joint angulations during dynamic gait ${ }^{(4)}$. Evidence that supports this argument includes reduced angular speed in spastic muscles during isolated joint movement ${ }^{(5)}$.

Motor dysfunction is one of the most frequently encountered problems after a stroke. Motor deficit is characterized by hemiplegia or hemiparesis of the opposite side of the cerebral hemisphere. Hypotonia is generally present immediately after stroke, and has a short duration. Very rarely, hypotonia may persist indefinitely. Spasticity emerges in about $90 \%$ of the cases and triggers an increased resistance to passive mobilization, which hinders or makes active movement impossible, and makes voluntary motor activity difficult with a deficit in movement amplitude and muscle strength ${ }^{(1)}$.

The gait pattern of hemiparetic patients varies according to the anatomical site, extent of the lesion, compensatory mechanisms developed, degree of muscle tone, preserved selective motor control, balance, and possible sensitivity modifications ${ }^{(3)}$.

Hemiparetic gait is common in patients with spastic hemiparesis and displays alterations in speed, cadence, symmetry, time, and stride length, maladjustments as to posture, balance and protective reaction, alterations in muscle tone and as to the pattern of neural activation, primarily on the paretic side, characterized by difficulties in initiation and duration of strides and in determining how much muscle strength will be necessary to walk ${ }^{(6)}$.

The use of water in treating sensory-motor dysfunctions caused by stroke is an ancient practice ${ }^{(4)}$. Treatment in a therapeutic pool is based on a few physical principles that direct the intervention of the physical therapist. Fluctuation and water density may facilitate or resist movements, sustain or dislocate the body ${ }^{(7,8)}$. The hydrostatic pressure helps to decrease weight load, to resolve edema, and may serve as a respiratory exercise ${ }^{(9,10)}$. Viscosity causes resistance to dislocation $^{(11)}$.

Variations in the aquatic environment, such as the production of turbulence, create an interesting medium for working on static and dynamic balance ${ }^{(12)}$. Movement in aqueous medium may be modified in numerous ways, creating diverse therapeutic situations ${ }^{(11,13)}$.

Among the results of published investigations, there are confirmed therapeutic effects of hydrotherapy, especially benefits such as increased range of movement, decreased muscle tension, relaxation, analgesia, improved circulation, absorption of inflammatory exudate and debridement of lesions, as well as increments in muscular strength and resistance, reeducation of paralyzed muscles, enhancement of balance and proprioception, besides improvement in functional activities and gait. Muscle spasms may be reduced by heat of water, helping to lessen spasticity. The authors further sustain that immersion in water leads to decreased muscle tone, while pain may be reduced by thermal stimuli. Additionally, immersion in water facilitates joint mobility, related to reduction of body weight ${ }^{(14)}$.

\section{OBJECTIVE}

To assess the functional mobility of stroke patients over the period of 12 hydrotherapy sessions.

\section{METHODS}

To conduct this study, we used the Timed Up and Go (TUG) test, which has provided good results, for instance the balance test that involves some functional maneuvers, such as getting up from a chair, walking, turning around, and sitting down again ${ }^{(15)}$.

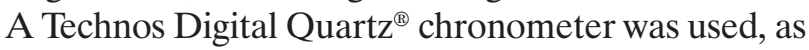
well as an YP2151/8P reference counter to assess walking time of the patients before and after therapy. Also used was a standard chair in which the patients initiated the test, and then transferred to a standing position.

The TUG test was utilized at the beginning and end of hydrotherapy for a total of 12 therapy sessions. This test evaluates the functional mobility of the individual, including items such as balance, gait speed, and getting up from a sitting to a standing position (when timing is begun), walking $3 \mathrm{~m}$, returning the $3 \mathrm{~m}$ and sitting on the chair again until their backs lean against the back of the chair (when timing is stopped) ${ }^{(16,17)}$.

As an intervention, standardized hydrotherapy exercises were performed by the research subjects, including stretching, muscle strengthening, and balance and walking training, within the limits of needs and capacity of each study individual.

Included in the study were patients who presented with diagnoses of ischemic stroke and/or hemorrhagic stroke with a hemiparetic predominance, with ages 5 to 85 years and walking with any type of aid (cane, crutches and/or walker).

Excluded from the study were patients presenting with associated pathologies that could compromise the performance of the task, with cognitive deficits, wheelchair users, and those who did not agree with the Informed Consent Form, as per Resolution \# 196/96 of the National Committee on Ethics in Research.

The inclusion of patients of different and discrepant ages, such as 5 and 85 years, was based on the need for the test to be used in individuals capable of walking and following instructions, according to the inclusion and exclusion criteria cited above.

The present study was directed towards comparing the functional mobility performance of each patient with him/herself, not considering diagnostic differences (ischemic stroke/ hemorrhagic stroke), the side affected, or differences in age. 
This study was approved by the Research Ethics Committee of the Hospital Israelita Albert Einstein (HIAE), under Protocol \# 09/1133.

\section{RESULTS}

Seventeen stroke patients were selected who engage in hydrotherapy at the HIAE. Seven of these were excluded, since they did not meet the defined inclusion criteria. The 10 remaining patients ( 8 men) formed a group with supervised gait and affected hemibody (right or left side). The representation of these data may be found on table 1 .

Table 1. Clinical data of study participants

\begin{tabular}{lcccc}
\hline Patient & Sex & Age & Involved side & Gait (FIM) \\
\hline Patient 1 & M & 67 & Left & FIM 6 \\
Patient 2 & M & 84 & Right & FIM 5 \\
Patient 3 & F & 7 & Right & FIM 6 \\
Patient 4 & M & 55 & Right & FIM 6 \\
Patient 5 & M & 83 & Left & FIM 5 \\
Patient 6 & M & 47 & Right & FIM 5 \\
Patient 7 & M & 64 & Right & FIM 6 \\
Patient 8 & F & 22 & Right & FIM 6 \\
Patient 9 & M & 57 & Left & FIM5 \\
Patient 10 & M & 66 & Right & FIM5 \\
\hline
\end{tabular}

FIM: Functional Independence Measure.

Table 2 shows the mean time of the test performance within each session. Therefore, it indicates the mean test time during pre-therapy and mean test time posttherapy obtained within each session, over the 12 hydrotherapy sessions (short-term).

Table 2. Mean of pre-therapy and post-therapy considering each of the 12 hydrotherapy sessions (short term)

\begin{tabular}{llc}
\hline Patient & $\begin{array}{c}\text { Mean } \\
\text { (pré- and post-therapy) }\end{array}$ & $\begin{array}{c}\text { Time } \\
\text { (seconds) }\end{array}$ \\
\hline Patient 1 & Mean (pre-therapy) & $44^{\prime \prime}$ \\
& Mean (post-therapy) & $41^{\prime \prime}$ \\
Patient 2 & Mean (pre-therapy) & $71^{\prime \prime}$ \\
& Mean (post-therapy) & $56^{\prime \prime}$ \\
Patient 3 & Mean (pre-therapy) & $8^{\prime \prime}$ \\
& Mean (post-therapy) & $7^{\prime \prime}$ \\
Patient 4 & Mean (pre-therapy) & $16^{\prime \prime}$ \\
& Mean (post-therapy) & $15^{\prime \prime}$ \\
Patient 5 & Mean (pre-therapy) & $29^{\prime \prime}$ \\
& Mean (post-therapy) & $29^{\prime \prime}$ \\
Patient 6 & Mean (pre-therapy) & $134^{\prime \prime}$ \\
& Mean (post-therapy) & $79^{\prime \prime}$ \\
Patient 7 & Mean (pre-therapy) & $11^{\prime \prime}$ \\
& Mean (post-therapy) & $10^{\prime \prime}$ \\
Patient 8 & Mean (pre-therapy) & $12 "$ \\
& Mean (post-therapy) & $11^{\prime \prime}$ \\
Patient 9 & Mean (pre-therapy) & $73^{\prime \prime}$ \\
& Mean (post-therapy) & $85^{\prime \prime}$ \\
Patient 10 & Mean (pre-therapy) & $27^{\prime \prime}$ \\
& Mean (post-therapy) & $27^{\prime \prime}$ \\
\hline
\end{tabular}

Table 3 shows the comparison of the long-term performance of each study patient, that is, over the period of the 12 sessions, comparing the pre-test of the first day of assessment with the post-test of the last day of assessment.

Table 3. Comparing the pre-test of the first assessment with the post-test of the last assessment

\begin{tabular}{|c|c|c|}
\hline Patient & Before/after 12 sessions & Time (seconds) \\
\hline \multirow[t]{2}{*}{ Patient 1} & Before 12 sessions & $52 " 34$ \\
\hline & After 12 sessions & $36 " 51$ \\
\hline \multirow[t]{2}{*}{ Patient 2} & Before 12 sessions & 61"83 \\
\hline & After 12 sessions & $54 " 03$ \\
\hline \multirow[t]{2}{*}{ Patient 3} & Before 12 sessions & 8"31 \\
\hline & After 12 sessions & $7 " 06$ \\
\hline \multirow[t]{2}{*}{ Patient 4} & Before 12 sessions & $22 " 03$ \\
\hline & After 12 sessions & $15 " 69$ \\
\hline \multirow[t]{2}{*}{ Patient 5} & Before 12 sessions & $34 " 67$ \\
\hline & After 12 sessions & $29 " 58$ \\
\hline \multirow[t]{2}{*}{ Patient 6} & Before 12 sessions & 101"11 \\
\hline & After 12 sessions & $76^{\prime \prime}$ \\
\hline \multirow[t]{2}{*}{ Patient 7} & Before 12 sessions & $14 " 51$ \\
\hline & After 12 sessions & 9"53 \\
\hline \multirow[t]{2}{*}{ Patient 8} & Before 12 sessions & $13 " 84$ \\
\hline & After 12 sessions & $11 " 55$ \\
\hline \multirow[t]{2}{*}{ Patient 9} & Before 12 sessions & 89"17 \\
\hline & After 12 sessions & $88 " 7$ \\
\hline \multirow[t]{2}{*}{ Patient 10} & Before 12 sessions & $37 " 9$ \\
\hline & After 12 sessions & $24 " 03$ \\
\hline
\end{tabular}

Within this context, comparing the pre-test of the first evaluation day and the post-test of the last evaluation day, it was noted that all ten patients decreased their long-term time averages, therefore, they improved their performance.

Figure 1 shows the interferences that the sector of aquatic physical therapy caused in applying the TUG test. Complaints were recorded on each test applied to the patients.

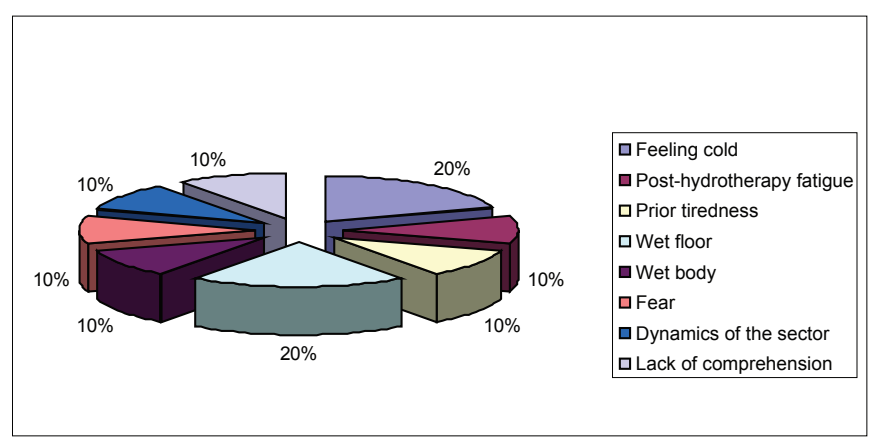

Figure 1. Interferences of the sector in the Timed Up and Go test

In the short-term evaluation, that is, when the mean was calculated for pre- and post-therapy of the 12 sessions, results showed two patients that maintained the same performance time for carrying out TUG and 
one patient that increased the time to perform the same activity, as is shown on table 4.

Table 4. Patients who maintained or increased time in performance of the test when checking the mean time of each therapy within 12 hydrotherapy sessions

\begin{tabular}{llc}
\hline Patient & $\begin{array}{c}\text { Mean } \\
\text { (before/after therapy) }\end{array}$ & Time (seconds) \\
\hline Patient 5 & Mean (before therapy) & $29^{\prime \prime}$ \\
\multirow{2}{*}{ Patient 9 } & Mean (after therapy) & $29^{\prime \prime}$ \\
& Mean (before therapy) & $73^{\prime \prime}$ \\
Patient 10 & Mean (after therapy) & $85^{\prime \prime}$ \\
& Mean (before therapy) & $27^{\prime \prime}$ \\
& Mean (after therapy) & $27^{\prime \prime}$ \\
\hline
\end{tabular}

\section{DISCUSSION}

According to the data obtained from the CVA patients in this study, when the comparison was made between the pre-test of the first evaluation with the post-test of the last evaluation, we noted that all patients decreased their respective times. This fact gives us the information that, in the long run, aquatic physical therapy may improve the functional mobility of stroke patients ${ }^{(18)}$. For the short-term, that is, when calculating the mean among the 12 pre- and post-therapy sessions, the results pointed out patients who maintained the same performance or who increased their time of performance of the TUG.

Within this context, we may associate the lack of decrease in the short-term testing performance time possibly to the complaints and interferences that the sector of hydrotherapy presented during the application of the TUG test, since these same patients obtained an improvement, that is, a decrease in time to carry out a task when the first day of evaluation was compared to the last (long-term).

The TUG test was carried out within the sector of aquatic physical therapy of the HIAE, following the criteria standardized in the validation study of this same test ${ }^{(16,17)}$; however, during the time of evaluations, we noted interferences in the sector of hydrotherapy in the application of the test at some point, affecting the patterns established by the article that validates $\mathrm{TUG}^{(16)}$. The following interferences were complaints mentioned by patients after applications of the test: feeling cold, post-hydrotherapy fatigue, prior tiredness, wet floor, wet bodies, fear, dynamics of the sector, and lack of comprehension of the test.

In order for the result of an evaluation performed within a sector of physical therapy to be the most reliable possible, we felt the need to resolve the components interfering in its application. Therefore, in future studies, we could have a safer method of evaluation and consequently, results that are more consistent and precise.
With this, for the use of the TUG test in the sector of aquatic physical therapy, we suggest that the patient perform the test wearing his/her habitual clothing before and after the aquatic physical therapy activity; before the test, it is important that the evaluation site be totally dry and tranquil; besides verbal instructions, the test could be demonstrated by the rater before the patient performs his part, for better understanding of what is required; some form of fatigue index could be applied before and after the test, so that prior fatigue does not interfere in the performance - if the patient is already very tired, the test should not be performed on that day; the more anxious patients or those with restricted time to remain in the sector should also be excluded from the test.

These measures serve as precautions and would not alter the standard of the test described in its validation study ${ }^{16)}$.

\section{CONCLUSION}

The results obtained in this study showed that all patients with stroke sequelae experienced improvements in their functional mobility performance during the 12 hydrotherapy sessions, comparing the first day of evaluation with the final day of the $12^{\text {th }}$ session.

These data evidence that a program of exercises in a therapeutic pool may be beneficial for improving performance of functional mobility in patients with stroke.

We suggest that in future studies, the test be applied in such a way that the environment does not hinder the mobility of patients, so that we may collect increasingly correct data on the condition of functional mobility of stroke patients after treatment in a therapeutic pool.

\section{REFERENCES}

1. Flansbjer UB, Holmbäck AM, Downham D, Patten C, Lexell J. Reliability of gait performance tests in men and women with hemiparesis after stroke. $J$ Reahabil Med. 2005;37(2):75-82.

2. Radanovic M. Características do atendimento de pacientes com acidente vascular cerebral em hospital secundário. Arq Neuropsiquiatr. 2000;58(1):99-106.

3. Fellows SJ, Kaus C, Thilmann AF. Voluntary movement at the elbow in spastic hemiparesis. Ann Neurol. 1994;36(3):397-407.

4. Knutson E, Mårtensson A. Dynamic motor capacity in spastic paresis and its relation to prime mover dysfunction, spastic reflexes and antagonist coactivation. Scand J Rehab Med. 1980;12(3):93-106.

5. Corcos DM, Gottlieb GL, Penn RD, Myklebust BM, Agarwal GC. Movement deficits caused by hyperex citable stretch reflexes in spastic human. Brain. 1986;109(5):1043-58.

6. Schuster RD, Zadra K, Luciano M, Polese FC, Mazzola D, Sander I, et al. Análise da pressão plantar em pacientes com acidente vascular encefálico. Rev Neurocienc. 2008;16(3):179-83. 
7. Campion MR. Hidroterapia: princípio e prática. São Paulo: Manole; 1999.

8. Le Veau B, Lissner W. Biomachanics of human motion. 2a ed. Philadelphia: Saunders; 1997.

9. Becker BE, Cole AJ. Terapia aquática moderna. São Paulo: Manole; 2000.

10. Morris DM. Aquatic rehabilitation of the neurologically impaired client. In: Ruoti $R G$, Morris DM, Cole AJ. Aquatic rehabilitation. Philadelphia: Lippincott; 1997. p.103-24.

11. Francarolli JL. Análise mecânica dos movimentos gímnicos e esportivos. 3a ed. Rio de Janeiro: Cultura Médica; 1998.

12. Blomfield J, Friecker P, Fitch K. Texboob of science and medicine in sport. Vol. III. Champaign: K Human Cinetics Books; 1992: 5.

13. Cunningham J. The Halliwick method. In: Ruoti RG, Morris DM, Cole J. Aquatic rehabilitation. Philadelphia: Lippincott; 1997. p. 305-32.
14. Hanson B, Norm A. Exercícios aquáticos terapêuticos. São Paulo: Manole; 1998:

15. Paula FL, Júnior A, Drummond E, Prata H. Teste timed up and go: uma comparação entre valores obtidos em ambientes fechado e abertos. Fisioter Mov. 2007;20(4):143-8.

16. Podsiadlo D, Richardson S. The timed "Up \& Go": a test of basic functional mobility for frail elderly persons. J Amer Geriatr Soc. 1991;39(2):142-8.

17. Richard WB. Reference Values for the timed up and go test: a descriptive meta-analysis. J Geriatr Physical Ther. 2006;29(2):64-8.

18. Navarro AS. Reabilitação e terapia aquática aplicada no acidente vascular encefálico. In: Jakaitis F. Reabilitação e terapia aquática: Aspectos clínicos e práticos. São Paulo: Roca; 2007. p. 192-210. 